\title{
Toleration as the Balance Between Liberty and Security
}

\author{
Anna Elisabetta Galeotti ${ }^{1}$ D $\cdot$ Federica Liveriero $^{2}$ (D)
}

Received: 27 September 2020 / Accepted: 27 January 2021 / Published online: 2 March 2021

(c) The Author(s) 2021, corrected publication 2021

\begin{abstract}
Traditionally, an adequate strategy to deal with the tension between liberty and security has been toleration, for the latter allows the maximization of individual liberty without endangering security, since it embraces the limits set by the harm principle and the principle of self-defense of the liberal order. The area outside the boundary clearly requires repressive measures to protect the security and the rights of all. In this paper, we focus on the balance of liberty and security afforded by toleration, analyzing how this strategy works in highly conflictual contexts and sorting out the different sets of reason that might motivate individual to assume a tolerant attitude. We contend that toleration represents a reliable political solution to conflicts potentially threatening social security when it is coupled with social tolerance. Hence, we examine the reasons the agents may have for endorsing toleration despite disagreement and disapproval. In the range of these reasons, we argue that the right reasons are those preserving the moral and epistemic integrity of the agent. The right reasons are however not accessible to everyone, as for example is the case with (nonviolent) religious fundamentalists. Only prudential reasons for toleration seem to be available to them. And yet, we argue that an open and inclusive democracy should in principle be hospitable towards prudential and pragmatic reasons as well, which may potentially lay the grounds for future cooperation. We conclude therefore that the tolerant society has room for the fundamentalists, granted that they do not resort to violence.
\end{abstract}

Keywords Toleration $\cdot$ Peaceful coexistence $\cdot$ Liberty rights $\cdot$ Agential integrity Fundamentalist attitude

Anna Elisabetta Galeotti

elisabetta.galeotti@uniupo.it

Federica Liveriero

federica.liveriero@unipv.it

1 Department of Humanities, University of Piemonte Orientale, Vercelli, Italy

2 Department of Political and Social Sciences, University of Pavia, Pavia, Italy 


\section{Setting the Problem}

Within the liberal tradition, toleration represents the standard solution to conflicts concerning clashes of values, religious doctrines and ways of life. The principle of political toleration recommends the political authority to confront conflicts between groups with non-interference in their religious and moral convictions, cultural practices and ways of life, if there is no disruption for law and order, and if the rights of all other citizens are respected. ${ }^{1}$ In other words, toleration has proved to be an adequate strategy to deal with the tension between liberty and security, since the democratic response to clashes among members of the polity should grant the security and physical integrity of citizens while at the same time minimizing the limitation of liberty rights of each one. But what about instances in which the balance between liberty and security is in danger? Take for example the challenge posed by threats of terrorist attacks and of harm from hateful people for contemporary democratic societies. In analyzing these extreme cases, it appears that the maximization of individual liberty, allowed by the principle of toleration, has clear boundaries beyond which toleration ought to stop. The boundaries are represented by the principle of self-defense of the political order and by the harm principle: actions and practices putting the political order at risk, on the one hand, or harming third party, on the other, are thus excluded from the area of toleration. ${ }^{2}$ The two principles are uncontentiously subscribed by all scholars of liberty and toleration, even though their interpretation is a matter of ongoing controversy. Without getting now into this issue, the area outside the boundary of toleration clearly requires repressive measures to protect the security and the rights of all. In this paper, however, we will not discuss the repressive measures that become necessary when toleration fails, but we will instead focus on the balance of liberty and security afforded by toleration, wondering how it works and how it is sustained by which individual attitudes. Indeed, the state, granting equal liberty to all, requires toleration of its members in their reciprocal relations, that is, it requires that members of the polity withhold their conflicts and disagreements and respect each other's liberty. ${ }^{3}$ Yet, toleration represents a

\footnotetext{
1 We are using here the term citizen - interchangeably with members of the polity-in a generic sense, meaning the set of individuals living in the same territory, engaging in social relations between one another and having to abide by the decisions of political institutions. For the overall goal of this paper we do not need to specify the formal status of the members of the polity that happen to live in the same territory. Hence, our general definition applies to immigrants, refugees, non-citizen residents as well as formally recognized citizens.

2 The principle of self-defense of the political order was first stated by John Locke (1991 [1685]), while the harm principle was presented by John Stuart Mill (1973 [1859]).

3 Some scholars dispute that political toleration, that is toleration by the liberal democratic state, can ever be the case, given that premise to toleration is disapproval of some opinion/behavior by a social party, and given that the liberal state should be neutral and not disapproving of anything within the bounds of the law (Horton 1996: 36; Jones 2007: 98; Newey 1999: 123-127). There are instead other authors who hold a view of toleration dispensing with disapproval, either simply endorsing the "live and let live" motto (Balint 2017), or as a way of accommodating normative diversity (Scheffler 2010). Finally, some scholars hold that toleration coexists with neutrality, for there are still questions about which the political institutions are the disapproving party granting toleration to some citizens (Farrelly 2003; Jones 2007; Kühler 2019; McKinnon 2013; Newey 2013). We hold that disapproval is indeed a condition of toleration, and yet, political toleration is not simply a residual issue in liberal democracy.
} 
reliable political solution to conflicts potentially constituting a threat to social security only when it is supplemented by social tolerance. For, even if political toleration is a duty for citizens, it may in fact be coupled with acts of social intolerance. In fact, although the disputed practices cannot be banned by any social agent, for only the political authority has the coercive power to interfere or refrain to interfere, social agents may nevertheless display forms of social intolerance, by means of the social power of stigmatization, exclusion and intimidation towards the disapproved party. And social intolerance fuels social insecurity, making the political order less stable and open to harmful incursions. Therefore, we must examine the reasons that agents may have for endorsing toleration despite disapproval, and granting the balance between security and liberty. ${ }^{4}$

In the first part of the paper, we will investigate which reasons social agents have to withhold their power of interference and assume a tolerant attitude, and, more specifically, whether such reasons, which are in fact second-order reasons, are not simply strategic but normative and stable. We will argue that the right reasons for toleration are those which preserve the moral and epistemic integrity of the agent, for in this case she has strong motivations to implement the regime of liberty and security for everyone. However, as we shall see, the right reasons for toleration are not accessible to everyone, and the open and inclusive democratic society must do with prudential and pragmatic reasons as well, which mitigate conflicts and potentially lay the grounds for future cooperation.

In the second part of the paper, we will investigate which reasons in favor of toleration-if ever — can be available to individuals holding a fundamentalist general posture. Under the heading of fundamentalism, a number of positions and attitudes are in fact comprised, ranging from terrorism to acquiescence with democratic society. Even though fundamentalist terrorism has significantly jeopardized national and international security in the last decades and have been a pressing issue of our time, we will not focus on this phenomenon, which falls beyond the boundaries of the tolerable. We will rather take up the case of religious fundamentalists who are not violent, but who, nevertheless, appear to be immune to the reasons for toleration that we will outline in the first part of the article. ${ }^{5}$ In search of reasons acceptable for religious fundamentalists, we shall look into the proposals by two scholars of

\footnotetext{
Footnote 3 (continued)

Political toleration implies precisely that the dislike among two social parties is dealt with by a political decision to refrain to interfere with the object of dislike, within the boundary of the harm principle (Galeotti 2019).

${ }^{4}$ In the literature, some authors have clearly stated that the inquiry on toleration is not exhausted by conceptual analysis. Instead, a normative theory is required as well, for an inclusive democratic system should also worry about which kind of reasons are provided in support of the tolerant act by institutions and/or citizens, since the very same action can be tolerated for right reasons or instead through a disrespectful and patronizing pose. See Audi (2011), Galeotti (2002).

5 By religious fundamentalism, in general, we mean a mode of religious conviction of different persuasions that leads its holders to be willing to shape the public sphere according to their sets of beliefs regardless to disagreement with others. In this paper, we specifically focus on the epistemic attitude generally shared by religious fundamentalists, without engaging with an analysis of their faith-related motifs and a nuanced outline of fundamentalism with regard to different religious faiths and creeds.
} 
toleration and conclude that the reasons they offer the fundamentalist are effective only in connection with values that are not part of the religious fundamentalist outlook. Should we then conclude that religious fundamentalists are doomed to intolerance? It appears, in fact, that the paradigmatic fundamentalist's outlook does not afford religious fundamentalists either to find internal reasons for toleration or to accept reasons proceeding from bracketing their religious faith. However, we conclude the paper with an optimistic stance, claiming that religious fundamentalists can still resort to strategic reasons for toleration. Their allegiance may be less stable, and their participation less committed to democratic ethos, and yet liberal democracy must be flexible concerning agents' attitudes toward the polity, given that the quest for security ought not to overshadow the crucial role of liberty. In conclusion, if violence and terrorism cannot be tolerated, the case of non-violent fundamentalists is different and we can in principle reach a peaceful coexistence with them even though the tolerance they display is not exactly what would be desirable from the normative perspective.

\section{Analysis of Agential Reasons for Toleration}

The reason for toleration recommends the agent to suspend the reason for disagreement with the other agent and to refrain from using the power at her disposal to put a burden on the other agent with whom she disagrees. From the point of view of the tolerator, why tolerating an act or a belief that one believes to be wrong and untrue is a value is far from obvious. The solution of this puzzle, verging on the paradoxical, has been at the center of all moral analyses of toleration. ${ }^{6}$ The conundrum can be solved if the reasons for toleration are thought of as second-order reasons with reference to the first-order reasons for disagreement. In turn, second order reasons can either engage with the object of controversy directly-and in that case the reasons for toleration are intrinsic to the object of conflict-or can exclude the firstorder reason on grounds of different kinds of consideration-and in that case the reasons for toleration are exclusionary and extrinsic to the disagreement. ${ }^{7}$

Reasons for toleration can thus be classified as follows:

a. Prudential reasons. Prudential reasons are extrinsic reasons derived by the intention to comply with the civic duty to reciprocally tolerate each other for selfinterested reasons.

b. Pragmatic reasons. Beyond the civic duty to tolerate each other, agents may have pragmatic reasons to be socially tolerant, such as a preference for social peace or the value of pluralism. These are typical cases of exclusionary, extrinsic reasons,

\footnotetext{
${ }^{6}$ Brenda Cohen (1967) defines the issue of the justification of toleration as the paradox of toleration, for the agent finds herself trapped between her moral reasons, suggesting intervening, and the reasons for toleration recommending self-restraint. It is however disputed whether toleration really implies a paradox (Newey 1999). On the justification of toleration see Mendus (1988).

7 The notion of exclusionary reason comes from Joseph Raz (1990).
} 
recommending to put aside the disagreement, and to act on different kinds of considerations.

c. Moral reasons. Agents can furthermore choose social toleration because of the value of autonomy or the value of equal respect deemed of a higher order than the reasons for disagreement, or by a moral disposition to be open towards other people and their difference (Forst 2013; Newey 1999). In this case, the reasons for toleration are not exclusionary, but rather overriding the reasons for the disapproval of the other side. Yet moral reasons do not directly engage the conflict over truth-matters involved in the controversy.

d. Epistemic reasons. This last kind of reasons, which we are going to analyze in the following section, instead engage directly with the object of the controversy hence setting the ground for an epistemic rationale for toleration.

Most theories of toleration have discussed the issue of the moral justification of toleration, thus directly or indirectly facing the problem of the moral integrity of the tolerator. In this respect, either toleration is thought to follow from moral reasons of a higher order, thus overriding the reasons for disapproval (Forst 2013; Mendus 1988, 1989), or is conceived of as an aretaic virtue of the character meaning the attitude to be well disposed and open-minded towards other people different from oneself (Newey 1999). In either case, the moral integrity of the tolerator is granted. Few scholars instead have taken up the issue of the tolerator's epistemic integrity, ${ }^{8}$ and yet it is theoretically as serious as the problem of moral integrity. If an agent, facing disagreement with another agent, is convinced of the truth of her first-order reasons, and believes that the other agent's beliefs are false, how can she tolerate them without conflicting with her own epistemic states? Actually, she may have purely strategic reasons for toleration. In that case, she keeps her disapproval of the other party untouched, tolerating the other party's conviction as a second best, as a purely prudential move under the circumstances, but also potentially ready to switch from toleration to intolerance under favorable circumstances. In this case, her epistemic integrity is not questioned by the agent's forbearance, but toleration turns out unstable. Alternatively, can she adopt toleration for less unstable reasons, for example for moral intrinsic reasons, without ending up epistemically divided between her convictions and the acceptance of erroneous beliefs? One possibility may be for the agent to become skeptical concerning moral convictions, so that she may endorse toleration of the opposite opinion without being epistemically divided. Yet, if she became skeptical, then her views would be as worthy as the views of her opponent, hence toleration would be superfluous for the conflict would be dissolved. The issue

\footnotetext{
${ }^{8}$ Rainer Forst is an exception to this trend. In chapter 11 "The finitude of reason" of Toleration in Conflict (2013), he faces what he labels as the relativization of the truth paradox. His proposed solution is based on the distinction between ethical judgements and moral judgments. The former are reasonable, but rejectable, while moral principles are such that no reasonable person can reject them. The reasons for disapproval belong to ethical judgments while the reasons for toleration are properly non-rejectable reasons. Hence, in Forst view there is no epistemic contradiction between holding ethical reasons, believing them true, and nevertheless being tolerant of contrasting reasons, given the rejectable nature of the matter of disagreement about ethical reasons.
} 
that we are going to pursue then concerns whether an agent, facing entrenched disagreement and convinced of the truth of her views, can be tolerant for non-extrinsic reasons without being torn between her first-order reasons for disapproval and her second-order reasons for tolerating the opinion contrary to the one she holds.

The distinction between reasons of different order is fundamental for our analysis, since our goal is to focus on the strictly epistemic reasons that agents facing entrenched disagreement often employ in the attempt either to solve the impasse or to manage the conflicts arising from the unresolved disagreement. Specifically, firstorder epistemic reasons are reasons directly supporting a specific belief the agent holds to be correct. In this section our analysis focuses on second-order epistemic reasons, therefore looking at the epistemic distinction between believing that $p$ and having second-order reasons concerning the degree of justifiability (or certainty) of the belief that $p$. In order to grasp the distinction between epistemic reasons of different orders, let us introduce what is called the doxastic presupposition of justification. According to the doxastic presupposition, the epistemic role of justification is not exhausted by the introduction of a set of reasons ' $R$ ' that provides a propositional justification for the belief that $p$. Rather, any comprehensive justification should involve a doxastic analysis that assesses whether agent $\mathrm{S}$ actually has grounded her belief that $p$ on the reasons that propositionally justify it. In order to evaluate the justifiability of S' belief about $p$ fully, we have to assess both the set of reasons ' $\mathrm{R}$ ' that are available to $\mathrm{S}$ for believing that $p$ justifiably, and the deliberative performance actually provided by $\mathrm{S}$ in assuming $p$ as a valid belief within her doxastic system of beliefs.

The analysis of the doxastic processes employed by agents is a good starting point to assess epistemic second-order reasons. ${ }^{9}$ Since doxastic aspects are always involved in our epistemic processes, it appears that two different agents, Sarah and Mark, might share first-order reasons in support of the belief that $p$, but doing so with different levels of confidence, given their own sets of second-order epistemic reasons on the matter. ${ }^{10}$ Also, more importantly, an analysis of the epistemic relevance of second-order reasons coupled with an exposition of the doxastic presupposition allows one to conclude that Sarah might be doxastically justified in holding the belief that $p$, even when the belief that $p$ is not epistemically warranted from a non-doxastic perspective.

When debating over complex evidence, agents tend to disagree. They disagree both on the matter at stake (believing that $p$ or believing $\sim p$ ) and on the reliability of their justificatory processes, therefore debating the epistemic second-order reasons they present in support of their different beliefs. Since it is really unlikely-if not impossible - that any agent can claim a full appraisal of the evidence at stake,

\footnotetext{
${ }_{9}$ For further analyses see Brink (1989), Feldman (2002), Turri (2010).

10 The doxastic presupposition clearly makes sense within an internalist account of epistemic justification. We do not have room to provide a comparison between internalist accounts and externalist accounts of epistemic justification. Rather, apart from epistemic reasons in support of the internalist view, we want to stress that the issue of epistemic integrity related to the act of tolerating a belief (or an act based on a belief) we deem wrong or dislikeable is more pressing within an internalist framework. Hence, it makes sense to assume this epistemic framework in our analysis.
} 
very often agents end up disagreeing not just about diverging beliefs per se, but also about the tenability of the reasons in support of these beliefs. From the epistemic perspective, the only solution for solving the disagreement is to provide conclusive reasons in favour either of the belief that $p$ or of the belief that $\sim p$. There are, however, at least two orders of concern regarding this strategy. First, many epistemic arguments can be advanced showing that evidence is 'too complex' to be attained by agents fully - with certainty. Consider, for example, the diachronic and social aspects of our belief formation processes (Sosa 2010) and the fact that disagreement is brought about by agents employing different systems of epistemic norms while reasoning about the same piece of evidence. Second, two aspects of disagreement over evaluative matters must be stressed: (i) there is no final criterion to establish which agent is actually more justified than others-in her or his doxastic set of beliefs-in supporting the right system of epistemic norms (Goldman 2010); (ii) the strategy of referring to experts, usually regarded as reliable in factual matters, is not available in the evaluative domain, for it is doubtful that agents would agree on the epistemic authority to cast a judgment regarding $p$ and $\sim p .^{11}$

Such concerns can be addressed referring to the fallibilist account of knowledge. As well-known, fallibilism is an epistemic stance according to which the kind of knowledge attained by agents is indeed compatible with the possibility of error. In other words, given that agents' epistemic processes for disclosing evidence can never grant certainty, errors cannot be in principle ruled out from genuine claims to knowledge. This conclusion follows from the fact that the reasons an agent holds in her doxastic system of beliefs may possibly be very good, but never warranted as conclusively true. In order to clarify this point, a distinction should be traced between two understandings of 'knowing':

\section{If $\mathrm{S}$ knows $p$, then $\mathrm{S}$ is not mistaken about $p$.}

2. If $\mathrm{S}$ knows $p$, then $p$ cannot be false.

Fallibilism accepts (1) and rejects (2). Definition (2) implies a too high epistemic standard, that is, a Thesis of Infallibility sustained by the Impossibility of Error Argument, according to which "to know something requires that it be that sort of thing that you could not be mistaken about" (Feldman 2002: 125). A fallibilist account of knowledge maintains that it is possible for agent $\mathrm{S}$ to be justified in believing that $p$, even if $S^{\prime}$ full body of evidence for $p$ does not necessarily entails the truth of $p$.

This epistemic analysis is relevant for understanding which sort of second-order epistemic reasons can motivate agents to act tolerantly. Our main thesis in this section is that the obligation to tolerate partly depends upon an epistemic argument in support of a general attitude of humility and respect for others' view derived by an

\footnotetext{
11 The core problem lying at the heart of the debate concerns whether two people can, on the basis of the same evidence, reasonably come to different conclusions. It is important to note that such debate relate with the discussion concerning the nature of evidence, specifically with the opposition between the Uniqueness thesis and the Permissiveness thesis. According to the former, a body of evidence justifies one single doxastic state, whereas the latter says that the overall body of evidence may justify more than one belief, therefore allowing a sort of epistemic relativism.
} 
acknowledgment of the fallibility shared with other parties. ${ }^{12}$ In order to push for this conclusion, in the next section we will differentiate among epistemic reactions that agents can have when facing genuine disagreement with agents that hold a symmetrical stance toward them. And that is precisely the case in a democratic setting.

In case of genuine disagreement over public matters, agents tend to hold mutually incompatible positions and, granted the relevance of the doxastic presupposition, they do so with at least what they deem to be reasonable doxastic reasons in support of their beliefs. Moreover, as said, public disagreements over evaluative matters cannot usually be solved thanks to the appeal to external authorities that are publicly acknowledged by all the agents involved in the conflict. ${ }^{13}$ It appears then that, prima facie, beliefs that are mutually incompatible can still be sustained with a good degree of credibility and tenability starting from agent-relative doxastic systems of beliefs. These forms of entrenched disagreement are hard to deal with, since neither party can give up their position without making cognitive changes that are felt to be impossible, or alienating, or even a threat to their sense of who they are. How can then we move from this stalemate to any intrinsic reason to act tolerantly toward other agents holding diverging beliefs, values and ideals?

In the growing literature concerning the epistemology of disagreement, many authors have reasoned about which is the adequate epistemic response when agents face qualified reasonable disagreement. Agents face qualified reasonable disagreement when:

(a) they hold mutually incompatible positions,

(b) each has a reason to hold the belief they do,

(c) it is extremely hard (if not impossible) for a rational person judging the disagreement to establish with a public procedure who has the epistemic authority to make claims that count as conclusive reasons for solving the disagreement.

Epistemologists mostly have distinguished two possible reactions to the fact of qualified reasonable disagreement. According to the Conciliatory View (Christensen 2007; Elga 2007; Feldman 2006, 2007; Lackey 2010), the fact that an epistemic peer ${ }^{14}$ disagrees with me with regard to the evaluation of the same piece of evidence

\footnotetext{
${ }^{12}$ For a technical analysis on the notion of epistemic parity that brings about similar conclusions, see Robert Audi (2011).

13 The normative constraint of public justifiability plays a fundamental role in our argument against the possibility of referring to a non-doxastic standpoint in order to solve evaluative disagreements adequately. In deeply disharmonious contexts as contemporary democracy we maintain that the reference to an external authority—independent from the agential doxastic perspectives-will hardly result to be publicly justifiable for all. Therefore, such strategy is not available as a solution to solve evaluative disagreements peacefully, because any reference to epistemic authorities would itself be contested.

${ }^{14}$ We are aware that epistemologists have concentrated on ideal circumstances in which epistemic peers, namely agents that possess similar epistemic abilities and are also more or less equal with respect to their familiarity with the body of evidence and the informational set, reasonably end up sustaining different conclusions. Obviously, the circumstances of politics are not at all ideal and hardly citizens can be considered epistemic peers. However, we believe that this debate can prove useful in the normative analysis of the management of disagreement in political settings.
} 
is a good second-order reason to 'bite the bullet' and at least question the epistemic processes that led me to believe that $p$. A strong interpretation of the conciliatory view calls for a revision of my belief in the attempt to split the difference and give equal weight in the evaluation of both mine and others' opinions (Gelfert 2011). A less demanding interpretation requires that I reconsider the level of epistemic trust I have in the belief that $p$, with no need to revise the belief itself. By contrast, the Steadfast View claims that, given the absence of an external epistemic authority acknowledged by all, a better doxastic response is to 'stick to my own guns' and not revise or reconsider the trust in my belief. Such a view claims that I can keep believing the truthfulness of my belief, regardless of the qualified disagreement with a peer. Authors provide different reasons in support of this strategy, such as the fact that higher-order evidence concerning the other party epistemic standpoint does not count (Kelly 2005), or they refer to the ineliminable aspects of the first-person standpoint and argue that we have good epistemic reasons to self-trust our own perspective, since it is indeed ours (Enoch 2011; Foley 2011; Wedgwood 2010).

According to the analysis of toleration provided in this paper, one issue that has not been properly investigated is whether agents can maintain their epistemic integrity while assuming a tolerant attitude toward beliefs, acts and attitudes they dislike and/or believe grounded in false beliefs. In this respect, the conciliatory view appears more apt to provide epistemic reasons in favor of a tolerant attitude. Stressing the social aspects of belief formation processes, the conciliatory view rejects epistemic dogmatism as the inadequate response to disagreement from the epistemic perspective. We can go further and connect the 'conciliatory attitude' with the claim that epistemic modesty is the appropriate standpoint in contexts where the appraisal of evidence is always contested (Bistagnino and Zuolo 2018; Peter 2013). Being epistemically modest does not mean that agents are not ready to fight for their own opinions or beliefs, rather it means that they can do so while still accepting the unquestionable fallibility of our epistemic processes qua human beings.

We hold that, when facing qualified persisting disagreement, agents have sound second-order reasons in support of diminishing — even minimally — the degree of confidence in their first-order beliefs. This epistemic attitude of modesty is grounded in a counterfactual argument: an epistemically reasonable Sarah is ready to accept the possibility that in case the evidence at stake was directly and fully accessible and her epistemic capacities infallible her present belief that $p$ might indeed turn out to be false and Mark's belief that $\sim p$ true. According to our epistemic account, Sarah can take the counterfactual argument as a second-order reason in favor of a modest epistemic attitude toward her doxastic system of beliefs, without endangering her epistemic and agential integrity in believing that $p$ (Brink 1989: 92-95; Feldman 2002).

At first sight, an objection to our argument is that members of the polity are not actual epistemic peers and, even more importantly, that social agents tend to dismiss other parties' agential and epistemic virtues. However, a crucial tenet of democratic legitimacy is that each member of the polity should be treated with equal respect, and that, in order to respect their agency properly, their opinions should be granted fair hearing. Even if in a democratic context, citizens are not required to see and treat each other as epistemic peers, yet the deliberative setting in which agents exchange 
opinions in the democratic arena imposes the moral duty of treating each other on an equal footing. If we couple this normative precondition of democratic systems with the meta-epistemic standpoint of modesty regarding the tenability of our evaluative beliefs, we can draw the conclusion that reasonable agents have epistemic reasons for partly diminishing their confidence in their own beliefs and for not dismissing the other parties' beliefs as completely unjustified. The kind of mutual acknowledgment that is envisioned in such exchanges is firstly morally grounded in the principle of equal respect and then sustained by epistemic reasons as well, derived from the recognition of our shared fallibility as epistemic agents (Liveriero 2020; Leland and van Wietmarschen 2012; Peter 2013).

We argue that the attitude of epistemic modesty can be included in the ideal of reasonableness, a crucial feature of liberal citizenship, thus providing an intrinsic epistemic reason in favor of a tolerant attitude toward other citizens we strongly disagree with. Briefly, the practical virtue of reasonableness is a fundamental concept in the literature concerning political liberalism and democratic legitimacy (Boettcher 2004; Habermas 1995; Quong 2011; Rawls 1993). Reasonableness is a crucial civic virtue allowing agents to cooperate notwithstanding the persistent disagreement that characterizes democratic societies. Reasonable members of the polity share the following features: (i) they are aware of the normative constraint of reciprocity; (ii) they are ready to restrain themselves from employing strictly private reasons while debating political matters; (iii) they are conscious of the epistemological limits we all share qua epistemic fallible agents.

Consistently with the general epistemic framework we defend in this work, we hold that a reasonable agent is aware of the limitations of humans' doxastic processes for establishing knowledge and, consequently, she is ready to recognize the right of other parties to disagree with her on evaluative matters. ${ }^{15}$ In sum, reasonable agents have intrinsic epistemic reasons to be tolerant of ideas, opinions and values they do not share and, more importantly, genuinely dislike. The epistemic dimension of reasonableness, if interpreted in this way, does not impose a demanding standard of epistemic rationality on agents engaged in public deliberative processes. Rather, this reading involves a normative request for reasonable citizens to undertake an attitude of epistemic modesty while deliberating public matters with agents with whom they disagree. These considerations are crucial for a liberal conception of democracy, because they provide agents with epistemic reasons in favor of toleration. Epistemic reasons for toleration, while preserving the epistemic integrity of agents, contribute to political stability and to civic friendship. Reasonable citizens, in respecting other citizens as free and equal members of the same cooperative

\footnotetext{
${ }^{15}$ It is worth highlighting that our argument in favor of the attitude of epistemic modesty around which we build our notion of toleration for intrinsic epistemic reasons relies on the recognition of fallibilism as the most adequate account of human knowledge. Fallibilism does not coincide with skepticism or relativism. Fallibilism is a rather lesser demanding epistemic standpoint that does not require us to take a stance regarding the ontological status of moral facts or about the impossibility of justifying any belief at all. We also maintain that the epistemic analysis we propose is compatible with a technical reading of the burdens of judgment introduced by John Rawls (1993) in order to provide epistemic support for the virtue of reasonableness (Liveriero 2015).
} 
scheme, must be able to respect the intellectual and evaluative autonomy granted to any member of the constituency qua citizen.

To conclude, there are second-order reasons in favor of toleration as a positive social attitude and of intellectual modesty as an epistemic attitude that are grounded in the epistemic analysis of our fallible epistemic abilities. A reasonable member of the polity has second-order reasons, both moral and epistemic, that justify a tolerant attitude, notwithstanding the genuine disagreement she faces with other agents. But what about individuals who are not reasonable though? How do they confront entrenched disagreement with others? With reference to disagreement, members of the polity are unreasonable if a. they tend to show an unshakeable self-trust in their first-person standpoint and b. their set of second-order reasons supporting the belief that $p$ are usually not affected by the contrasts with the diverging views of other citizens. In the next section, we will confront the case of religious fundamentalists who represent a typical example of unreasonable members of the polity.

\section{Is Toleration Precluded to the Religious Fundamentalist?}

Among unreasonable members of the polity, religious fundamentalists present a special challenge to the toleration of convictions and viewpoints different from their own and to a respectful coexistence in pluralist democracies. Generally speaking, fundamentalists are characterized by a dogmatic attitude that leads them to resist systematically the second-order reasons that support adopting a tolerant attitude toward people holding views that they disapprove. ${ }^{16}$ Convinced of the alleged objectivity and truthfulness of their doxastic standpoint, they altogether reject the fallibilist counterfactual clause. As a result, they find no firsthand reason to tolerate what they see as false, wrong, and perverting the moral fabric of society. Consequently, they may be perceived as representing a threat to political order and security, so as to provoke intolerant institutional responses to their perceived intolerant attitude. ${ }^{17}$ Yet, are such responses justified in the context of democratic principles and are they adequate to keep the balance between liberty and security? And is it true that fundamentalists cannot be but intolerant? In this regard, a first distinction should be drawn between people holding a fundamentalist view and people ready to act out of his/ her fundamentalist position. As said, no democratic state can tolerate violence and terrorist acts, which go beyond the boundary of the tolerable, hence we shall not be concerned with them. A different problem is however represented by people simply holding and expressing a fundamentalist view, which is what we are focusing on. We will not engage here with an analysis of their faith-related motifs and a nuanced outline of fundamentalism with regard to different religious faiths and creeds, but

\footnotetext{
16 We like to stress that in our view what characterizes fundamentalism is not a given doctrine, but rather the dogmatic attitude displayed in support of any given doctrine. While similar dogmatic stances can be displaced regarding various issues, such as the animal rights fanaticism, the no-vax position, the climatechange denialism, what is special about religious fundamentalism is its comprehensiveness, embracing all spheres of individual and social life.

17 For a discussion of the possibility of tolerating acts of intolerance see Galeotti (2002: 137-150).
} 
rather will concentrate on how fundamentalist believers relate to democratic society and vice versa, given that our problem here is how toleration can be sustained confronting the fundamentalist challenge. In this respect, by religious fundamentalism, in general, we intend a dogmatic mode of religious conviction of different persuasions that leads its holders to have a strong preference to live in a society shaped by the rules and principles derived from their set of beliefs. Since they live however in a liberal democracy, they have to adopt different strategies according to their numbers and strengths in that society. If they belong to the majority's religion, they may be willing to shape the public sphere according to their sets of beliefs regardless of disagreement with others. Examples of this kind of strategy are represented by a certain strand of fundamentalist Catholicism in historically Catholic countries, where the opposition to a law on divorce was fierce and long as well as more recently the opposition to public recognition of civil unions. If fundamentalists are instead a minority, clearly lacking the force to shape legislation, they have usually two different paths to accommodate to democratic society: if they are territorially based, they can ask certain exemptions and try to live their communal life as much as possible apart from the democratic society. This is, for example, the case of Amish communities in Pennsylvania and of Hasidic Jews in New York, who live mostly alienated from the surrounding society, following their own rules and principles and limiting their interaction with the external word as much as they can. In such cases, the toleration that such groups enjoy is different from the typical liberal toleration, and akin a sort of territorialism albeit within a democratic state. Toleration is a compromised solution, acceptable within definite boundaries, for it accommodates minorities estranged from the proper membership in the polity, and not relating on a reciprocal basis with other citizens. Finally, if the fundamentalist minority is scattered in a country or regional area, it is more difficult to live a secluded communal life, hence, mostly they have to adapt to the rules of the larger society and likely they have been victims themselves of forms of social intolerance. This is the case of fundamentalist Muslims living in the diaspora of Western democracy.

From the viewpoint of this work, namely how toleration can represent a proper balance between liberty and security, the last type of fundamentalists is the most relevant. If fundamentalists represent a hard-core group in the religious majority of a democratic country, such as Catholics in Italy, Ireland and Spain, they do not usually raise issues of security and terrorism, but rather issues of separation of state and church, and more generally issues of public reason. The discussion of how true believers can adopt public reasons without giving up their personal integrity, much debated in the last decades, will take us in a different direction from toleration, liberty and security. The second group of fundamentalists raises a lot of normative problems to liberal democracy, but do not represent a threat to security. By contrast, religious fundamentalists scattered in our society, where some of them have chosen to join forces with ISIS or with terrorist groups, are perceived as a potential threat to citizens' life and political stability. For this reason, we shall concentrate on this type of religious fundamentalism and ask whether (a) they can be tolerant, and whether (b) they can be tolerated.

In addressing the possibility for a religious fundamentalist to be tolerant, Susan Mendus (2008) has remarked that either toleration is unavailable for the 
fundamentalist or she must find reasons she can accept from within her perspective and such that do not question or weaken her faith. In other words, either the fundamentalist finds internal reasons to tolerate the error, or toleration is impossible for her. In order to understand why she reaches this conclusion, let's layout a reasonable epistemic outlook of the fundamentalist reasoning. The fundamentalist opposes what she sees as false, for different religious or non-religious views are contrary to the true word of God, and wrong too, for false beliefs imply a conduct and a lifestyle outside the precepts of the true religion. Moreover, the fundamentalist thinks that it is wrong to let the error be and propagate, for false doctrines pollute society and may condemn even more souls to damnation that would otherwise be saved. In the eye of the religious fundamentalist, at stake there is eternal salvation that is the highest value and good for human beings. In this background, it is clear that the pragmatic reasons for toleration fail, for they imply bracketing the first-order reason for disapproval and the consideration of a different order of reasons such as the preference for peace or for the value of pluralism. Similarly, the moral reasons for toleration cannot in this case override the reasons for objection to false doctrines. For the fundamentalist does not acknowledge any moral or pragmatic reason of a higher order than salvation and implementing God's word and will.

Even though finding internal reasons for toleration looks very unlikely, Susan Mendus thinks that there are in fact epistemic arguments fit to persuade the religious fundamentalist in favor of toleration. Not surprisingly, Mendus's arguments are sophisticated reinterpretations of modern political doctrines, especially of Locke's Letter on Toleration, given that the seventeenth and eighteenth centuries doctrines precisely confronted the problem of religious conflict, of persecution and of violence for religious motives, and tried to persuade the true believer that toleration of dissenting views was not a compromise, but a principled solution. The most well-known argument for toleration advanced by Locke is the argument from the irrationality of persecution, according to which beliefs cannot be forced by coercion. This argument however has been deeply criticized by Jeremy Waldron (1991), among others, for empirical evidence shows that actually beliefs can be changed via coercion. Yet, as stressed by Mendus, holding true beliefs is not sufficient for religious salvation; it is also necessary to have acquired and to hold them in the right way (Mendus 2008: 26). Under this light, forcing the true beliefs on dissenters proves ineffective, and toleration appears a reasonable policy. More important than this argument, according to Mendus, is the argument from irrelevance or "impertinence" of persecution (Mendus 2008: 30). The argument from impertinence sanctions the separation between Church and State, respectively in matters of the soul's salvation, and in matters of peace and order. In turn, such separation is grounded on the argument that God, being infinitely good, for a crucial question as salvation, has endowed each person with the capacity to examine and decide for herself, and, by contrast, has not bestowed the magistrate with the authority to decide on the salvation of his subjects. Thus, God has granted equal epistemic authority to all human beings, so that each ought to look for the truth and salvation using his or her judgement, and no one else, be it a fellow believer or the state, has business in imposing his or her path to salvation on any other. 
Mendus holds that Locke's arguments drawing their force from within religion can speak to the contemporary fundamentalist as well for they do not threaten or weaken her convictions. Indeed Locke's arguments have the advantage to engage with the religious beliefs, and to provide reasons for toleration internal to the religious convictions, instead of asking the believer to bracket or put aside such convictions in name of other ideals she cannot acknowledge as superior. Yet, in order to work, these arguments are conditional on two assumptions: (a) the fundamentalist thinks his duty to save souls and not to eradicate the error; (b) he accepts the equal epistemic authority of anyone concerning the search for true salvation. ${ }^{18}$ In other words, Mendus's revisitation of Locke is appealing only to some religious believer who prioritizes souls' salvation of the erring people over suppressing the false doctrines, which was the main justification of persecution during the religious wars following Reformation. In case the religious believer's crucial goal is rather to destroy the infidels and eradicate the wrong religion and worldview, Mendus's argument is ineffective. Moreover, in many religious persuasions, Christian or otherwise, epistemic authority over religious matters, included salvation, is far from being equally distributed, and it is usually monopolized by the Church and its clergy, or by prophets, rabbis or other authorized intermediaries. ${ }^{19}$ Hence, in order to bite, the argument from impertinence requires that epistemic equality is previously accepted by the religious fundamentalist as a God's gift. Yet it is hard to reconcile the acknowledgement of epistemic equality with the fundamentalist's highest degree of trust in her (first-order) beliefs. In other words, the religious fundamentalist can be persuaded by Locke's arguments if he or she is already reasonable and accepts that each person has a right (bestowed by God) to search for salvation according to her light. Yet if she is reasonable in this sense, she is a devout religious believer but hardly a fundamentalist according to our previous definition.

Let us now consider another argument aimed at persuading the fundamentalist to toleration, advanced by John Tate (2016). He too is providing reasons that do not challenge the religious beliefs of the fundamentalist, deriving in fact from those very beliefs. Like Mendus, Tate rephrases an argument that Locke developed in his expansion of the Letter on Toleration, while discussing with Jonas Proast and trying to convince the Anglican theologian of the good of toleration. According to Tate, the Lockean argument that true religious believers can accept is epistemic and refers to the distinction between knowing the truth, and possessing the truth via faith. Only true knowledge can be transmitted for it is irresistible, not true faith, for faith is not

\footnotetext{
18 Humeira Iqtidar (2020), discussing the work of Muslim scholar Ghamidi, and its specifically non-liberal path to toleration, shows that the tolerant attitude is grounded on the virtue of Khushu, that is humility in considering other people in a non-judgmental way. Actually, humility corresponds to the attitude of epistemic modesty, and makes all humans equal. Despite the significant difference between Ghamidi and Locke's argument, both refer to the epistemic equality of human beings, and moreover Ghamidi endorses epistemic modesty as justification for a general attitude of restraint on judging others' actions.

19 In almost all religions, however, there are interpretative traditions challenging the epistemic authority of the Church or the clergy and proposing something closer to a statement of epistemic parity coupled with a requirement of epistemic modesty, so as to open the way to internal epistemic reason for toleration. As an example, see again Iqtidar (2020).
} 
grounded on evidence that all rational cognizers must acknowledge. Locke's skeptical argument concerning the 'knowledge' of the true religion leaves intact the faith in the true religion and the related conviction of its truth. The distinction between knowing something and having faith in something justifies the exclusion of coercion for errors that cannot be known for sure, prescribing instead toleration. In Tate's view, such reasoning is in principle acceptable by the true believer for it does not question that her faith is true, only that it can universally be known to be true. It follows that faith cannot be imposed given that it cannot provide non-rejectable evidence and grounds for any rational cognizer.

Even though Tate's argument, like the previous one, takes the perspective of the true believer seriously, and tries to provide him or her with internal reasons, this epistemic argument cannot convince the religious fundamentalist to embrace toleration instead of intolerance. In order to accept the distinction between knowledge and faith as different paths to truths, the fundamentalist must first be convinced that the truth arrived at by faith may ever diverge from the truth reached by knowledge. But, even if she might acknowledge that the access to truth follows different paths, truth is in any case, and for everyone, true, and, while the faithful lacks the lever for convincing the unfaithful of the word of God, the latter, being nonetheless true, gives the believer no reasons to refrain to act on its basis. In order to have reason to withhold her intervention with wrong beliefs or false religion, she must admit either that, lacking final evidence, her faith may be false - as shown in the fallibilist counterfactual clause-, or that only known truths are rightfully imposed for, in that case, reason cannot reject knowledge. Neither arguments are however consistent with the dogmatic position of the religious fundamentalist.

In sum, both Mendus and Tate's appeals to toleration are not providing the religious fundamentalist with sufficient internal reasons for toleration. As we have seen, both arguments work only in conjunction with other beliefs and values, such as the priority of the salvation of infidels' souls over the eradication of errors and purification of the world, or the preference for peaceful coexistence of differing values, or the epistemic distinction between knowledge and faith. These supplementary beliefs and values are hardly part of the internal reasons of the religious fundamentalist, and yet they are necessary to transform the above arguments in actual reasons for toleration. Shall we then conclude that the religious fundamentalist can be anything but intolerant? We have said that neither pragmatic nor moral reasons work for the fundamentalist for there are no higher order reason or principle trumping her religious doctrines. Yet, there are alternatives to intolerance; two main options seem available. Firstly, the fundamentalist may acquiesce with religious errors out of necessity. Acquiescence is not a tolerant posture, but rather a non-obstructive behavior out of powerlessness. (King 1976). It is far from ideal, especially since it is not stable: the acquiescent person may easily turn intolerant under change of circumstances. Alternatively, she may be tolerant for strategic reasons: in this case, the secondorder reasons do not engage with the object of the controversy, but merely appeals to prudential motivation to forebear the religious error. The two possibilities are actually very similar in practice, but while in the first case, the agent feels forced to noninterference, in the second case, the agent has chosen forbearance even if just for prudential reasons. Both are unstable, with a slightly different degree of instability. 
The fundamentalist who has chosen toleration for prudential reasons has apparently excluded to resort to intolerant acts, while the acquiescent fundamentalist may be more prone to resort to intolerance given the opportunity. Even though epistemic and moral reasons in favor of toleration are not accessible to the religious fundamentalist, political institutions should not exclude the fundamentalist from a peaceful cohabitation within a liberal society, for not only she can coexist and practice her faith in peace, but also, in the due course of time, she may come to value the freedom afforded in a tolerant environment. Symmetrically, even though she does not share the public ethics of a liberal society, she should not be subjected to the social intolerance of the majority. In fact, the principle of equal respect and the attitude of reasonableness provide sufficient reasons for the virtue of social tolerance, whether or not the tolerant stance is reciprocated by the fundamentalist on the same terms.

\section{Conclusions}

Contemporary democracy is characterized by a high degree of pluralism and diversity, potentially nurturing conflicts and undermining security. In this work, we have contended that toleration represents the ideal balance between the right to security and the right to freedom, insofar as it allows for peaceful coexistence of diversity without requiring extra limitations of liberty. Yet, toleration works within limits beyond which the liberty of some may threaten the security and the rights of others and the very persistence of the democratic order. The boundaries of a tolerant society are hardly clear-cut, and many fuzzy cases are located at its fringe. For this reason, we have tried to map the tolerant society from the center to the fringe through the analysis of the various reasons agents have to be tolerant of what they dislike or disapprove. As we have seen, toleration can be endorsed by members of the polity for a large range of reasons from strategic to moral, to epistemic. We have shown that moral and epistemic reasons stabilize toleration and sustain maximal liberty without endangering anyone's rights and social security. Furthermore, moral and epistemic reasons for toleration preserve agents' integrity, since agents find them within their own set of moral and epistemic convictions.

This ideal solution is however not always available in a highly pluralistic society such as contemporary democracies and we hold that democratic societies should in principle be hospitable towards all sorts of reasons, even the ones providing an unstable support to democratic principles, at least until there is no recourse to violence. On the one side, filtering out strategic and pragmatic reasons for toleration would turn out too demanding on members of the polity. On the other, the exclusion of religious fundamentalists, if they have not committed harmful acts towards third parties, is unjustified for it breaches the liberal promise of openness and inclusion of everyone without moral distinctions among people. Moreover, it is counterproductive as well, for it can push the fundamentalist beyond the boundary of lawful conducts. Finally, it would imply an undue restriction of the area of toleration to those who are already reasonable, paradoxically transforming democratic societies in to quite illiberal ones. In other words, restricting toleration to those members of the polity that endorse it for the right reasons, may not deliver security within liberty, 
forcing the tip too much in favor of the right to security at the expense of rights to individual liberties.

Acknowledgement Earlier versions of this paper were presented at the Association for Social and Political Philosophy 2018 Annual Conference (LUISS University and Sapienza University, Rome) and at the Second Meeting of the Permanent Seminar on Practical Normativity (Collegio Ghislieri, Pavia). We are grateful to their audiences for lively discussions and useful feedback and criticisms. Special thanks to Robert Audi, Emanuela Ceva and Corrado Fumagalli for their written comments.

Author Contributions The two authors contributed equally to the original theses of the research work and in outlining the manuscript.

Funding Information that explains whether and by whom the research was supported. Open access funding provided by Università degli Studi del Piemonte Orientale Amedeo Avogrado. Federica Liveriero is grateful to the Italian National Operational Programme on "Research and Innovation" PON (2014 2020) that supported her research while she worked on this article. Grant Number: AIM1813255-1. CUP: B26C19000040001. Open access funding provided by Università degli Studi del Piemonte Orientale Amedeo Avogrado within the CRUI-CARE Agreement.

\section{Compliance with Ethical Standards}

Conflict of interest No conflict of interest.

Open Access This article is licensed under a Creative Commons Attribution 4.0 International License, which permits use, sharing, adaptation, distribution and reproduction in any medium or format, as long as you give appropriate credit to the original author(s) and the source, provide a link to the Creative Commons licence, and indicate if changes were made. The images or other third party material in this article are included in the article's Creative Commons licence, unless indicated otherwise in a credit line to the material. If material is not included in the article's Creative Commons licence and your intended use is not permitted by statutory regulation or exceeds the permitted use, you will need to obtain permission directly from the copyright holder. To view a copy of this licence, visit http://creativecommons.org/licen ses/by/4.0/.

\section{References}

Audi, R. 2011. Democratic authority and the separation of church and state. Oxford: Oxford University Press.

Balint, P. 2017. Respecting toleration. Oxford: Oxford University Press.

Bistagnino, G., and F. Zuolo. 2018. Disagreement, peerhood and compromise. Social Theory and Practice 44 (4): 593-618.

Brink, D.O. 1989. Moral realism and the foundations of ethics. New York: Cambridge University Press.

Boettcher, J.W. 2004. What is reasonableness? Philosophy \& Social Criticism 30 (5-6): 597-621.

Christensen, D. 2007. Epistemology of disagreement: the good news. Philosophical Review 116 (2): 187-217.

Christensen, D., and J. Lackey, eds. 2013. The epistemology of disagreement. Oxford: Oxford University Press.

Cohen, B. 1967. An ethical paradox. Mind 76 (302): 250-259.

Elga, A. 2007. Reflection and disagreement. Nô̂s 41 (3): 478-502.

Enoch, D. 2011. Not just a truthometer: taking oneself seriously (but not too seriously) in case of peer disagreement. Mind 19 (476): 953-997.

Farrelly, C. 2003. Neutrality, toleration and reasonable agreement. In Neutrality, toleration and democracy, ed. D. Castiglione and C. McKinnon, 111-123. Dordrecht: Springer.

Feldman, R. 2002. Epistemology. Upper Saddle River: Prentice Hall. 
Feldman, R. 2006. Epistemological puzzles about disagreement. In Epistemology futures, ed. S. Hetherington, 216-236. Oxford: Clarendon Press.

Feldman, R. 2007. Reasonable religious disagreements. In Philosophers without gods: Meditations on atheism and the secular, ed. L. Antony, 194-214. Oxford: Oxford University Press.

Foley, R. 2011. Intellectual trust in oneself and others. Cambridge: Cambridge University Press.

Forst, R. 2013. Toleration in conflict. Past and present. Cambridge: Cambridge University Press.

Galeotti, A.E. 2002. Toleration as recognition. Cambridge: Cambridge University Press.

Galeotti, A.E. 2019. Glen Newey's critique of political toleration. Biblioteca della libertà 225-226: 15-39.

Gelfert, A. 2011. Who is an epistemic peer? Logos \& Episteme 2 (4): 507-514.

Goldman, A. 2010. Epistemic relativism and reasonable disagreement. In Disagreement, ed. R. Feldman and T. Warfield, 187-215. Oxford: Oxford University Press.

Gutting, G. 1982. Religious belief and religious skepticism. Notre Dame: University of Notre Dame Press.

Habermas, J. 1995. Reconciliation through the public use of reason: Remarks on John Rawls's political liberalism. The Journal of Philosophy 92 (3): 109-131.

Horton, J. 1996. Toleration as a virtue. In Toleration: An elusive virtue, ed. D. Heyd, 28-43. Princeton: Princeton University Press.

Iqtidar, H. 2020. Is tolerance liberal? Javed Ahmad Ghamidi and the non-Muslim minority. Political Theory. https://doi.org/10.1177/0090591720956590.

Jones, P. 2007. Making sense of political toleration. British Journal of Political Science 37: 383-402.

Kelly, T. 2005. The epistemic significance of disagreement. In Oxford studies in epistemology, vol. 1, ed. J. Hawthorne and T. Gendler, 167-195. Oxford: Oxford University Press.

King, P. 1976. Toleration. London: Allen \& Unwin.

Kühler, M. 2019. Can a value-neutral liberal state still be tolerant? Critical Review of International Social and Political Philosophy. https://doi.org/10.1080/13698230.2019.1616878.

Lackey, J. 2010. A justificationist view of disagreement's epistemic significance. In Social epistemology, ed. A. Millar, A. Haddock, and D. Pritchard, 298-325. Oxford: Oxford University Press.

Leland, R.T., and H. van Wietmarschen. 2012. Reasonableness, intellectual modesty, and reciprocity in political justification. Ethics 122 (4): 721-747.

Liveriero, F. 2015. The epistemic dimension of reasonableness. Philosophy \& Social Criticism 41 (6): $517-535$.

Liveriero, F. 2020. Reasonableness as a virtue of citizenship and the opacity respect requirement. Philosophy and Social Criticism 46 (8): 901-921.

Locke, J. [1685] 1991. A Letter Concerning Toleration, eds. J. Horton and S, Mendus. London: Routledge.

McKinnon, C. 2013. Vertical toleration as a liberal practice. Social Theory and Practice 39: 1-18.

Mendus, S., ed. 1988. Justifying toleration: Conceptual and historical perspectives. Cambridge: Cambridge University Press.

Mendus, S. 1989. Toleration and the limits of liberalism. London: Macmillan.

Mendus, S. 2008. The Freilich lectures 2007. Religious toleration in an age of terrorism. Camberra: Australian National University.

Mill, J. S. [1861] 1973. On liberty. Indianapolis: Hackett.

Newey, G. 1999. Virtue, reason and toleration. Edinburgh: Edinburgh University Press.

Newey, G. 2013. Toleration in political conflict. Cambridge: Cambridge University Press.

Peter, F. 2013. Epistemic foundations of political liberalism. Journal of Moral Philosophy 10 (5): $598-620$.

Quong, J. 2011. Liberalism without perfection. New York: Oxford University Press.

Rawls, J. 1993. Political liberalism. New York: Columbia University Press.

Raz, J. 1990. Practical reason and norms. Princeton: Princeton University Press.

Scheffler, S. 2010. The good of toleration. In Equality and tradition, ed. S. Scheffler, 312-336. Oxford: Oxford University Press.

Sosa, E. 2010. The epistemology of disagreement. In Social epistemology, ed. A. Millar, A. Haddock, and D. Pritchard, 278-297. Oxford: Oxford University Press.

Tate, J. 2016. Toleration, skepticism and blasphemy: John Locke, Jonas Proast and Charlie Hebdo. American Journal of Political Science 60: 664-675.

Turri, J. 2010. On the relationship between propositional and doxastic justification. Philosophy and Phenomenological Research 80 (2): 312-326. 
Waldron, J. 1991. Locke's toleration and the rationality of persecution. In John Locke. A letter concerning toleration in focus, ed. J. Horton and S. Mendus, 98-124. London: Routledge.

Wedgwood, R. 2010. The moral evil demons. In Disagreement, ed. R. Feldman and T. Warfield, 216247. Oxford: Oxford University Press.

Publisher's Note Springer Nature remains neutral with regard to jurisdictional claims in published maps and institutional affiliations. 